\title{
SÍNTESE HISTÓRICO-LEGAL DA ADMINISTRAÇÃO E GESTÃO DA ESCOLA PÚBLICA NO BRASIL: DO PERÍODO COLONIAL À LDBEN/1996
}

\author{
SÍNTESIS HISTÓRICO-LEGAL DE LA ADMINISTRACIÓN Y GESTIÓN DE LA \\ ESCUELA PÚBLICA EN BRASIL: DEL PERÍODO COLONIAL A LA LDBEN/1996
}
HISTORICAL-LEGAL SYNTHESIS OF PUBLIC SCHOOL ADMINISTRATION AND MANAGEMENT IN BRAZIL: FROM THE COLONAL PERIOD TO LDBEN/1996

\author{
Sandra Regina Bernardes de Oliveira ROSA ${ }^{1}$ \\ Rita SCHANE ${ }^{2}$ \\ Sirley Terezinha FILIPAK ${ }^{3}$
}

RESUMO: Este trabalho é um estudo documental e bibliográfico, o qual apresenta a escola e a gestão das escolas brasileiras enquanto diferentes construções sócio-históricas e políticas, de instituição religiosa a instituição do Estado. A história e as leis permitem conhecer a organização, administração e gestão da escola pública no Brasil do período colonial à LDBEN/1996. O texto tem a finalidade de realizar breve retrospectiva e análise, a partir do pressuposto de que o passado explica o presente e nos aponta direções futuras.

PALAVRAS-CHAVE: Educação. Gestão. Organização. Sistema educacional.

RESUMEN: Este trabajo es un estudio documental y bibliográfico, que presenta la escuela y la gestión de las escuelas brasileñas como diferentes construcciones sociohistóricas y políticas, desde las religiosas hasta las instituciones estatales. La historia y las leyes permiten conocer la organización, administración y gestión de la escuela pública en Brasil, del periodo colonial a la Ley de Directrices y Bases de la Educación Nacional LDBEN/1996. El texto tiene la finalidad de realizar un breve retrospectivo y un análisis, a partir del presupuesto de que el pasado explica el presente y nos apunta hacia direcciones futuras.

PALABRAS-CLAVE: Educación. Gestión. Organización. Sistema educativo.

ABSTRACT: This work is a documentary and bibliographic study, which presents the school and the school management of Brazilian schools as different socio-historical and political constructions, as religious institution to State institution. The history and laws allow to know

${ }^{1}$ Pontifícia Universidade Católica do Paraná (PUC-PR), Curitiba - PR - Brasil. Doutoranda no Programa de Pós-Graduação em Educação (PPGE). ORCID: https://orcid.org/0000-0001-8451-3441. E-mail: bernardesrosa72@gmail.com

2 Pontifícia Universidade Católica do Paraná (PUC-PR), Curitiba - PR - Brasil. Doutoranda no Programa de Pós-Graduação em Educação (PPGE). ORCID: https://orcid.org/0000-0001-6389-5145. E-mail: rischane@gmail.com

${ }^{3}$ Pontifícia Universidade Católica do Paraná (PUC-PR), Curitiba - PR - Brasil. Professora Titular no Programa de Pós-Graduação em Educação (PPGE). Doutorado em Educação (PUC-PR). ORCID: https://orcid.org/00000003-4264-1626. E-mail: sirley.filipak@pucpr.br

RPGE- Revista on line de Política e Gestão Educacional, Araraquara, v. 25, n. 2, p. 1106-1118, maio/ago. 2021. e-ISSN: 1519-9029 DOI: https://doi.org/10.22633/rpge.v25i2.15112 
the organization, administration and management of public schools in Brazil from the colonial period to LDBEN/1996. The text has the purpose to perform a brief retrospective and analysis, from the assumption that the past explains the present and points us to future directions.

KEYWORDS: Education. Management. Organization. Educational system.

\section{Introdução}

No Brasil, a educação escolar foi iniciada pelos jesuítas com base em disciplina severa e rígida. Conforme descreve Azevedo (1976), a educação jesuítica do período colonial orientava-se para a uniformidade intelectual, com ensino dogmático e abstrato, não apresentava flexibilidade de ajuste às necessidades, os métodos eram autoritários e a rotina conservadora e controlada. Segundo o autor, essa forma de educação atendeu a sua época deixando fortes traços no processo educacional brasileiro. Neste contexto, o ensino no Brasil, em 1549, foi a catequização enquanto educação.

O ensino pensado pela Igreja Católica, que mantinha relação com o governo de Portugal, tinha como objetivo catequético, converter a alma do índio brasileiro à fé cristã. Escolas improvisadas, construídas pelos próprios índios; no entanto, as aulas lecionadas para os filhos dos colonos. Também eram atendidos de forma diferenciada os filhos de portugueses, descendentes de europeus que também frequentavam as aulas dos jesuítas, entretanto, recebendo um ensino aprofundado, que não se restringia à propagação do ensino religioso. A diferenciação do ensino para este público privilegiado era um pedido feito pela elite colonial que morava no Brasil.

\section{A educação escolar no Brasil no período Jesuíta}

Em 1599, foi elaborado e promulgado o Ratio Studiorum, documento de referência da Ordem Jesuítica, no qual constavam as normas pedagógicas da educação jesuítica a serem seguidas por todas as escolas da Companhia de Jesus, mesmo havendo diferenciação entre os ensinamentos repassados aos índios e aos filhos dos colonos. A educação jesuítica tentava seguir esta diretriz curricular: o Ratio Studiorum, com base no conteúdo planejado pela Igreja, a qual, também constava o ensino da gramática média, da gramática superior, das humanidades, da retórica, da filosofia e da teologia. A partir do ensino das letras, começava a se formar no país uma organização da sociedade hierarquizada pelo acesso ao ler e escrever. 
A educação letrada no Brasil colonial era direcionada somente aos homens, as mulheres não tinham acesso aos colégios e eram educadas somente para a vida doméstica e religiosa.

O período colonial brasileiro, baseado na grande propriedade e na mão-de-obra escrava, contribuiu com propostas educacionais para inovação do ensino, como cita Romanelli (1993, p. 42), que não foram efetivadas:

faltava para sua execução, além de uma infraestrutura institucional que pudesse assegurar-lhe a implantação, o apoio político das elites, que viam nessas ideias, uma ameaça perigosa à formação da juventude, cuja educação vinha, até então, sendo pautada nos valores e padrões da velha mentalidade aristocrático-rural.

Por ordem da Igreja Católica, em torno de 1750 houve expulsão dos jesuítas, comandada pelo então primeiro-ministro de Portugal, Marquês do Pombal, que significou uma remodelação do sistema de ensino brasileiro e a tentativa de deixar de lado a religião nos currículos.

Influenciado pelos ideais iluministas, Pombal tinha convicção de que era preciso modificar a educação em Portugal e no Brasil. E isso ocorre formalmente em 1772, com a chamada reforma pombalina. Após a instauração dessas mudanças, o Brasil dá seus primeiros passos na criação de um ensino público. A desestruturação da escola jesuíta, porém, fez com que os índios perdessem espaço no sistema de ensino, por outro lado, a reorganização tornou o professor uma carência histórica no país.

\section{Primeira lei brasileira que trata da educação}

Um dos momentos mais importantes da história da educação no Brasil ocorre com a chegada da família real ao Brasil, em 1808, fugida da Europa por conta da invasão a Portugal. Em um dos navios vindos da Europa, desembarcaram no Rio de Janeiro cerca de 60 mil livros que deram origem à Biblioteca Nacional. A presença da coroa portuguesa impulsionou alguns investimentos na área da educação, que culminaram na criação das primeiras escolas de ensino superior, com o objetivo de preparar academicamente os filhos da nobreza portuguesa e da aristocracia brasileira. Apesar de o país ter se tornado independente em 1822, a educação, durante o período Imperial, não contabilizou muitos avanços práticos.

A gratuidade do ensino, estabelecida por determinação da corte portuguesa, não representou, de fato, investimentos em construção de escolas com espaços físicos adequados, muito menos contratação de professores bem formados ou uso de métodos e materiais didáticos aprofundados. Os mais prejudicados pela falta de prioridade do investimento em

RPGE- Revista on line de Política e Gestão Educacional, Araraquara, v. 25, n. 2, p. 1106-1118, maio/ago. 2021. e-ISSN: 1519-9029 DOI: https://doi.org/10.22633/rpge.v25i2.15112 
educação foram as classes populares do país, sendo que os filhos das famílias mais ricas tinham acesso facilitado ao colégio e cursos em universidades de Portugal.

Em 1827, foi sancionada a primeira lei brasileira que tratava exclusivamente da educação. Tal lei foi o início de uma nova forma de organizar o ensino brasileiro. Seu texto, no artigo $1^{\circ}$, afirmava que "em todas as cidades, vilas e lugares mais populosos, haverá as escolas de primeiras letras que forem necessárias" (BRASIL, 1827).

A nova regra foi um marco para as meninas (mulheres), pois foi permitido sua presença, com os meninos, nas escolas de letras do Estado.

No artigo $6^{\circ}$, a lei versava sobre as matérias que os professores deveriam ensinar em sala de aula. Constava do texto da lei, o ensino da leitura, da escrita e da matemática, princípios de moral cristã da religião católica, além da história do Brasil. No mesmo texto, havia a previsão de que os professores considerados pouco qualificados para lecionar deveriam complementar a sua formação de forma individualizada, o Estado não bancaria a capacitação do docente. Neste ponto, o governo se isentou de investir e direcionar a capacitação dos profissionais de ensino, sendo que ainda predominavam os antigos professores decorrentes da reforma pombalina do século XVIII.

Em 1834, o governo monárquico inaugurou a primeira escola de formação de professores, a Escola Normal de Niterói. Durante os primeiros 50 anos de funcionamento, as escolas normais eram frequentadas quase que exclusivamente por homens. Durante o período regencial, ocorreu uma reforma na Constituição, um ato adicional instituído pelo governo, no qual foi definido que o ensino elementar, secundário e a formação de professores seriam de responsabilidade das províncias, e o ensino superior ficaria sob o poder central, fortalecendo a descentralização do ensino e a organização da educação no país (BRASIL, 1934).

\section{Dualidade do sistema escolar brasileiro}

A partir de marcos históricos como o Iluminismo, a Revolução Francesa, o Liberalismo e a Revolução Industrial a escola passou a ser um assunto do Estado, com medidas como a nacionalização das escolas e a criação de sistemas estatais de ensino. Desta forma a educação tradicional manteve-se durante este período como consequência do próprio modelo socioeconômico, que não havia sido alterado com o advento da República. De acordo com Azevedo (1976, p. 134): 
pensamento ou a decisão de realizar uma transformação radical no sistema de ensino para provocar uma renovação intelectual das elites culturais e políticas, necessárias às novas instituições democráticas.

Após a proclamação da República foi realizada a reforma do ministro da instrução, Benjamin Constant, realizada em 1890, com foco no ensino superior. As escolas de base não foram prioridades dos primeiros governos republicanos, somente poucas escolas de qualidade eram mantidas pelo governo federal com exclusividade para as elites. Sobravam para os menos favorecidos, os colégios do sistema estadual, que eram locais sem estrutura e com professores com pouca formação. Os professores acumulavam funções de gestão e de ministrar aulas, estando sujeitos ao cumprimento das diretivas emanadas do Estado, ao qual cabia a responsabilidade de administrar e fiscalizar as escolas públicas.

A situação política confusa neste início de década republicana, a insatisfação do povo, o descontentamento de setores políticos, levaram o governo federal a não tomar medidas imediatas que visassem uma organização de plano de governo. E a demora de tomada de medidas no campo educacional levou ao descontentamento àqueles educadores que participaram das reformas na década de 1920, os quais assinam, em 1932, o Manifesto dos Pioneiros da Educação Nova.

A partir do movimento da Escola Nova houve tentativa de mudar essa realidade. O ambiente educacional se fortaleceu com reformas estaduais inspiradas nas ideais escolanovistas de educadores como Anísio Teixeira, que despontaram como lideranças do movimento. A Escola Nova, no Brasil, ficou marcada pela tentativa de tornar a educação mais inclusiva e adotar um modelo mais moderno de ensino, voltado para uma educação prática da vida, tendo como base as ideias do filósofo americano John Dewey e também de educadores europeus, como Decroly, Montessori e outros. Também neste período, mesmo que com caráter privado, iniciava-se uma preocupação com a educação infantil.

É fundada na década de 1920, a Associação Brasileira de Educação (ABE), criada por Heitor Lira que promoveu os primeiros grandes debates sobre a educação em nosso país. Mesmo com esforços para tentar avançar na implantação de um sistema educacional consistente, persistia o analfabetismo entre jovens e adultos. De acordo com o IBGE, a taxa de analfabetismo na década de 1920, para pessoas a partir dos 15 anos, era de $65 \%$. O percentual baixou para metade da população somente na década de 1940 quando caiu para $40 \%$, o que representava cerca de 15 milhões de pessoas.

Em 1930 o governo ditatorial de Getúlio Vargas mesmo com o controle ideológico nas salas de aula, inicia um movimento em direção a um sistema organizado de ensino com a 
criação do Ministério da Educação, cujo Ministro foi Francisco Campos no ensino superior, sendo logo em seguida, a vez da reforma do ensino secundário e secretarias estaduais de Educação. Mas estas reformas são pequenas e, ainda, existe falta de medidas mais abrangentes, continuando a educação desvinculada do contexto histórico e sendo vista como fator determinante na mudança social, causando muitos conflitos entre os grupos de classe dominante.

Ao longo deste período é o pensamento conservador católico que impede as inovações propostas pelos Pioneiros da Escola Nova e que estão ligadas à burguesia em ascensão, enquanto os conservadores representam a aristocracia rural. No que se refere ao não questionamento do capitalismo dependente, à participação do Estado na educação e à importância da educação na reconstrução nacional, as propostas pedagógicas da ala católica, em alguns aspectos, convergem com as da Escola Nova.

O ensino laico representa, indubitavelmente, o primeiro passo para a concretização do controle estatal sobre a educação, circunstância que só poderia ser efetivada tendo em conta as dimensões organizacionais do processo educativo, isto é, através da implantação de um novo tipo organizacional, concretizado na escola pública. A partir deste momento, o Estado passa a controlar a educação. Uma administração centralizada permaneceria como um dos traços mais característicos da administração pública e da administração da educação, por meio da responsabilização pelas escolas públicas e fiscalização das escolas particulares.

A Constituição de 1934 foi a primeira a dedicar em seu texto, um capítulo sobre à educação. Fruto da forte centralização nacional que marcou o período da Era Vargas, o sistema educacional seguia as orientações e determinações do governo federal e a autonomia dos Estados era limitada e regulada. Em 1942, foi regulamentado o ensino industrial, surgem as escolas do Serviço Social da Indústria (SENAI), direcionadas, especialmente, às camadas pobres da população.

Nesse sentido, torna-se importante resgatar que a gestão democrática como princípio constitucional da educação pública surge a partir de lutas históricas. Embora na década de 1930 (AZEVEDO, 1976), o Manifesto dos Pioneiros da Educação Nova tenha apontado a necessidade de democratização da educação, a despeito de se fazerem presentes no documento concepções outras acerca desse conceito, tal conteúdo não foi tratado na Constituição de 1934, que inaugura, na legislação, a necessidade de "traçar as diretrizes da Educação Nacional” (Art. 5, inciso XIV) (BRASIL, 1934).

Todavia a educação apareceu na Constituição como "um direito de todos" somente após o governo de Vargas. No fim da década de 1940, as escolas secundárias têm forte 
expansão e, aos poucos, vão perdendo seu caráter elitista, embora o acesso ainda não fosse de todos. Segundo dados do Serviço de Estatística do Ministério da Educação e Cultura, em 1940, eram 155 mil frequentadores dessa etapa escolar. Dez anos depois, o número sobe para 365 mil. No ensino profissionalizante, também a quantidade de alunos aumenta.

$\mathrm{Na}$ década de 60, as ideias de Paulo Freire ganham repercussão nacional, em especial seus métodos de alfabetização e de educação da população carente. Em 1961 é promulgada a primeira Lei de Diretrizes e Bases da Educação (LDBEN), documento histórico que institui um núcleo de disciplinas comuns a todos os ramos.

Neste período, com as Leis 5540/68 e 5692/71 cresce a participação das mulheres no ensino público, a divisão entre os sexos fica quase metade a metade e em 1971, fica obrigatória a conclusão do primário grau fixado em oito anos, e passam a ser utilizados os termos $1^{\circ}$ grau e $2^{\circ}$ graus, esta segunda fase escolar, com um caráter mais técnico, seguindo o novo modelo de desenvolvimento associado ao capital internacional e que objetivava promover o desenvolvimento brasileiro.

Assim o Brasil sofreu um golpe militar em 1964, causando grandes repressões, cerceando a voz dos brasileiros e brasileiras, instituindo o silêncio e até mesmo a morte, (ROMANELLI, 1993).

Após a ditadura, até meados da década de 80 do século XX ressurgiu o pensamento democrático e o anseio da população pela participação nos desígnios do país, inclusive no campo educacional. Com a derrocada da ditadura, houve o envolvimento da sociedade, o modelo da gestão na escola abriu espaço para a comunidade e alargou os modos de nomeação dos diretores escolares.

Iniciou-se um novo panorama político que proporcionou aos cidadãos e cidadãs a participação na sociedade, possibilitando voz e voto nas decisões políticas e na escolha dos representantes.

Deste modo, um novo momento histórico é presenciado pelos brasileiros e brasileiras: a redemocratização do país.

Movimentos na sociedade são organizados como os dos trabalhadores, estudantes e políticos partidários, todos com o desejo de ignorar os Decretos e Atos Institucionais do governo militar e criar uma nova Constituição Brasileira.

Após os fortes embates, os constituintes representantes do povo, neste cenário de disputas, elaboram e promulgam a Constituição Brasileira em 5 de outubro de 1988, para muitos, como aquela na história brasileira que mais atende aos anseios populares. $\mathrm{O}$ povo 
através da referida Constituição, passou a escolher o presidente da república. O Brasil muda do poder militar para o poder neoliberal.

Com LDBEN de 1996, entrou em vigor a denominação de Ensino Fundamental e Ensino Médio. A mudança ocorrida incluiu ambos os períodos como etapas da educação básica, e integrou, oficialmente, a educação infantil, que ganhou mais relevância no cenário educacional. Essa estrutura permanece atualmente (BRASIL, 1996).

Com tal legislação enfatiza-se os conceitos de pluralidade de concepções pedagógicas, gestão democrática e autonomia de organização curricular, orientando a elaboração e implementação de novas propostas curriculares para as redes de ensino. Portanto, novas possibilidades para a organização do currículo, a partir da reflexão e desconstrução de conceitos historicamente interiorizados.

A organização do tempo escolar atual tem como matriz regulatória a LDBEN 9.394/1996 que determina em seu artigo 24, item I que "a carga horária mínima anual será de oitocentas horas, distribuídas por um mínimo de duzentos dias de efetivo trabalho escolar, excluído o tempo reservado aos exames finais, quando houver".

Apesar de a construção educacional brasileira ter uma trajetória de quase 500 anos, o país ainda enfrenta desafios na área, sendo o analfabetismo um deles. O Plano Nacional de Educação (PNE), por exemplo, estabelece que o problema deve ser erradicado até 2025. Números do Instituto Brasileiro de Geografia e Estatística (IBGE), porém, são desanimadores. Em 2017, foram computados 12 milhões de analfabetos, representando 7,2\% da população adulta.

Embora o Ensino Fundamental esteja praticamente universalizado no Brasil, o acesso à educação para crianças entre 4 e 5 , que se tornou obrigatório, é de $90 \%$. O dado é ainda menor nas faixas entre 15 e 17 anos, cuja taxa de escolarização é de 87,2\%.

A valorização do magistério e as condições de estrutura das escolas são exemplos de que avanços fazem-se necessários.

A dualidade continua com escolas muito precárias por todo país. A valorização do professor é um problema secular no Brasil, o que faz da qualidade do ensino, desde a educação infantil, nosso maior desafio.

\section{Administração e Gestão Escolar no Brasil, construções sócio históricas e políticas}

A administração escolar no Brasil adota os princípios da administração considerados no sistema capitalista, pois vivemos em uma sociedade capitalista. 
$\mathrm{Na}$ escola, esses princípios foram adotados com o intuito de fazer a educação alcançar maior eficiência, produtividade e êxito.

A administração deve ser entendida como resultado de um longo processo de transformação histórica, que traz as marcas das contradições sociais e dos interesses políticos em jogo na sociedade.

A contextualização da educação brasileira, a partir do referencial teórico, possibilita compreender como ela foi se constituindo e se transformando ao longo da história da educação, em função das transformações provocadas na sociedade em cada período histórico. Ou seja, ao invés de se partir de um conceito de administração abstrato e geral, deve-se entendê-la como expressão abstrata de relações que são "historicamente determinadas pelas relações econômicas, políticas e sociais, que se verificam sob o modo de produção capitalista [...]” (PARO, 1999, p. 18).

É o entendimento desse processo de transformação que possibilita entender como se deu a organização e a transformação do sistema educacional brasileiro, a forma como as escolas se constituíram, os regulamentos, as normas e as leis criadas para melhor organizar o seu funcionamento, as concepções filosóficas e pedagógicas que, em cada período, nortearam as inúmeras propostas de reformas educacionais; o modelo da gestão nas escolas brasileiras, foi um processo conduzido por fatores históricos e políticos.

Um contexto aliado à globalização e aos modelos educacionais de outros países apresenta desresponsabilização do Estado pelas escolas, descaracterizando a si própria e o princípio democrático, ficando a gestão correlacionada aos aspectos financeiros, sendo motivado pelos lucros, seguindo a tendência mundial.

Nesta síntese são percebidas as diferentes políticas educativas que fizeram o modelo de gestão educativa no Brasil.

Este trajeto, com enfoque nas questões do ensino, na administração e gestão das escolas, permite-nos concluir que à educação pública foi sendo atribuída uma importância crescente, quer pelo impacto fundamental que esta desempenha no avanço tecnológico e econômico do país, quer por representar um veículo de imposição ideológica, transformandose, assim, num instrumento de poder.

A Igreja e seus agentes tiveram muita importância na transmissão da cultura e do saber até que se interrompe o monopólio clerical da educação pública e se inicia a laicização do ensino, com o Estado assumindo um papel determinante na tentativa de um sistema educativo progressivamente democrático e igualitário. Entretanto, efetivamente, o modelo político e organizacional da escola esteve, durante décadas, desprovido de quaisquer 
estruturas democráticas e participativas, o diretor funcionando como um representante do poder central, um delegado de confiança política junto de cada escola.

Os ideais progressistas de educação são reassumidos na Constituição de 1946, na atribuição da discussão em torno das "diretrizes e bases da educação nacional” por uma comissão constituída por educadores de diversas tendências (SAVIANI, 2002). Entretanto, é após a reorganização partidária iniciada no final da década de 1970, que a gestão democrática vem a tornar-se princípio legal da educação pública, na Constituição Federal de 1988, art. 215, inciso VI (BRASIL, 1988).

Também com a Lei n. 9.394/96, de Diretrizes e Bases da Educação Nacional-LDBEN em seu art. $3^{\circ}$, inciso VII, ressoa o princípio constitucional da gestão democrática do ensino público, estabelecendo que esta deva ocorrer na forma da LDBEN e "da legislação dos sistemas de ensino" (BRASIL, 1996).

No art. 14, incisos I e II, fica disposto que as normas de gestão democrática dos sistemas de ensino deverão assegurar como princípios: a "participação dos profissionais da educação na elaboração do projeto pedagógico da escola" e "da comunidade escolar e local em conselhos escolares ou equivalentes".

A reflexão acerca dessa participação deve dar-se a partir do caráter da nossa Constituição: "Todo poder emana do povo, que o exerce por meio de representantes eleitos ou diretamente" (art. 1 ${ }^{\circ}, \S$ único) (BRASIL, 1988).

Desse modo, explicita que a democracia representativa não é suficiente; precisa de aperfeiçoamento com mecanismos de participação direta, com ampliação da cidadania.

Seguindo o ordenamento jurídico, o Plano Nacional de Educação (PNE) 2001-2011, aprovado por intermédio da Lei n. 10.172/2001 (BRASIL, 2001), além de reafirmar o conteúdo constitucional, apresentou, dentre os princípios de formação dos professores e valorização do magistério, a vivência de formas de gestão democrática.

No eixo de Financiamento e Gestão, define que cada sistema deveria implantá-los na forma de Conselhos de Educação, no âmbito do sistema; na forma de conselhos escolares com representação da comunidade educacional, no âmbito das escolas. A escolha de diretores é enunciada mediante garantia de competência e compromisso com a proposta definida pelos conselhos escolares. É também insistente a necessidade de controle social dos recursos por meio dos Conselhos de Educação. No documento, observa-se conteúdo voltado à necessidade de normatização da gestão democrática, às formas representativas de participação e ao controle dos recursos financeiros. 
Com a aprovação do PNE (2014-2024), a gestão democrática ganha ênfase. A Lei n. 13.005/2014 (BRASIL, 2014) a apresenta como princípio (art. $2^{\circ}$, VI) e como método de construção dos planos decenais de educação $\left(\operatorname{art} .8^{\circ}, \S 2^{\circ}\right)$ e define prazo de dois anos para que os entes federativos aprovem suas leis regulamentando-a. Além disso, o PNE tem uma meta (Meta 19) e oito estratégias especificamente relacionadas à gestão democrática, referentes à: constituição, formação e manutenção de colegiados (conselhos, fóruns, grêmios); participação das famílias e dos profissionais da educação; controle social e fiscalização dos recursos públicos e escolha de diretores, mediante mérito, desempenho e consulta pública.

Nesse sentido, tais mecanismos de participação começam pela escolha do gestor, via eleições diretas, que possibilitam a integração da comunidade escolar e a participação desta no desenvolvimento das ações didático-pedagógicas e técnico-administrativas, e na avaliação das mesmas. A eleição do diretor, a autoridade compartilhada com a gestão colegiada, conselhos de escola, com todos os segmentos da comunidade escolar: pais, alunos, professores, direção e demais funcionários, são passos para a gestão democrática e que, como todo processo de mudança, carrega desafios e superações da prática.

Para o recebimento dos recursos, a escola teve que constituir-se em uma administração colegiada, com participação da comunidade nas decisões da escola, pais, alunos, e profissionais da escola, o diretor escolar como gestor participativo para tomar decisões quanto os aspectos pedagógico, administrativo e financeiro; criou-se o conselho escolar, órgão colegiado responsável pela gestão da escola.

O Plano Nacional de Educação (PNE 2014/2024), também em sua meta 19 preceitua assegurar condições para a efetivação da gestão democrática da educação, associada a critérios técnicos de mérito e desempenho e à consulta pública à comunidade escolar, no âmbito das escolas públicas, prevendo recursos e apoio técnico da União para tanto (BRASIL, 2014).

\section{Considerações finais}

Gestão democrática na educação implica conhecimento, em mediação de conflitos, escutas, possibilidade de lidar com a coletividade, estar cotidianamente fazendo o enfrentamento dos dilemas advindos de um processo em meio a concepções e projetos societários diversos. 
Das leis à efetividade, um enorme hiato, pois foi por meio de lutas históricas que a gestão democrática chegou às normas, as disputas provenientes desse processo perpassam a continuidade progressiva dessa trajetória.

O Brasil, de uma economia agrária-comercial-exportadora passou a uma economia baseada na industrialização e no desenvolvimento tecnológico, não priorizando a educação em seus investimentos político-sociais e a estrutura educacional permaneceu inalterada. É necessário conhecer a História percorrida até nossos dias, para que se construa a partir dela, resultados dos trabalhos que foram desenvolvidos até o presente e propostas educacionais futuras para os cidadãos.

A sociedade se transforma permanentemente. Somos agentes dessa transformação, aprendemos com a história, articulando a instituição escolar como instrumento de construção de uma sociedade justa. Eis o desafio que se impõe a todo cidadão, porém, com maior responsabilidade àqueles que atuam profissionalmente na área educacional e, dentre estes os gestores escolares.

\section{REFERÊNCIAS}

AZEVEDO, F. A cultura brasileira. 5. ed. São Paulo, SP: Melhoramentos, 1976.

BRASIL. Constituição Política do Império. Lei geral da instrução pública. 1827. Disponível em: http://www.planalto.gov.br/civil 03/constituição/constituicao24.htm. Acesso em: 1 fev. 2020.

BRASIL. Constituição Federal de 1934. Brasília, DF: Planalto do Governo, 1934. Disponível em: http://www.planalto.gov.br/civil_03/constituicao/constituicao34.html. Acesso em: 1 fev. 2020.

BRASIL. Lei n. 5.540, de 28 de novembro de 1968. Fixa normas de organização e funcionamento do ensino superior e sua articulação com a escola média. Brasília, DF, 1968. Disponível em: https://www2.camara.leg.br/legin/fed/lei/1960-1969/lei-5540-28-novembro1968-359201-publicacaooriginal-1-pl.html. Acesso em: 25 mar. 2020.

BRASIL. Lei n. 5692, de 11 de agosto de 1971. Disponível em: http://www.planalto.gov.br/civil. Acesso em: 31 maio 2020.

BRASIL. Lei n. 9.394, de 20 de dezembro de 1996. Lei de Diretrizes e Bases da Educação Nacional. Estabelece as diretrizes e bases da educação nacional. Brasília, DF, 1996.

Disponível em: http://www.planalto.gov.br/ccivil_03/leis/19394.htm. Acesso em: 25 mar. 2020.

BRASIL. Lei Federal 13.005, de 25 de junho de 2014. Aprova o Plano Nacional de Educação - PNE e dá outras providências. Brasília, DF, 25. jun. 2014. Disponível em: 
http://www.planalto.gov.br/ccivil_03/_ato2011-2014/2014/lei/113005.htm. Acesso em: 17jun 2020.

PARO, V. H. Administração escolar. Introdução crítica. 8. ed. São Paulo, SP: Cortez Editora, 1999.

PARO, V. H. Gestão democrática da escola pública. São Paulo, SP: Editora Ática. 2002.

ROMANELLI, O. O. História da educação no Brasil (1930/1973). 15. ed. Petrópolis, RJ: Vozes, 1993.

SAVIANI, D. Política e educação no Brasil: o papel do Congresso Nacional na Legislação do Ensino. 5. ed. rev. Campinas, SP: Autores Associados, 2002.

\section{Como referenciar este artigo}

ROSA, S. R. B. O.; SCHANE, R.; FILIPAK, S. T. Síntese histórico-legal da administração e gestão da escola pública no Brasil: do período colonial à LDBEN/1996. Revista on line de Política e Gestão Educacional, Araraquara, v. 25, n. 2, p. 1106-1118, maio/ago. 2021. eISSN:1519-9029. DOI: https://doi.org/10.22633/rpge.v25i2.15112

Submetido em: $22 / 05 / 2021$

Aprovado em: 28/05/2021

Publicado em: 01/08/2021 